\title{
Field investigation and finite element modelling of a progressive debris slide in the Indian Himalayas
}

\author{
D. P. Kanungo, A. Pain, S. Sarkar, S. Sharma, \\ S. K. Jain \& Z. Ahmad \\ Geotechnical Engineering Division, \\ CSIR, Central Building Research Institute (CBRI), Roorkee, India
}

\begin{abstract}
The paper highlights the detailed field and laboratory investigation along with finite element modelling of a progressive debris slide along a highly vulnerable road stretch of Chamoli-Badrinath highway (NH-58) in Indian Himalayas. To investigate the failure process of the landslide, the slope was modelled along two different profiles using a finite element package PHASE $^{2}$ based on a 2dimensional elasto-plastic model for calculating stresses and displacements. The material properties for different layers on the slope were chosen from the laboratory test results of soil samples and available literature. Shear Strength Reduction (SSR) analysis was performed to determine the critical Strength Reduction Factor (SRF). It is observed that the critical SRF is 0.54 for left flank and 0.53 for right flank slope profiles. This indicates that the slope is highly unstable. The results show very good correlation with the observed field conditions. The locations of the landslide scars, from where the sliding processes have already been initiated, match exactly with the FE analysis result. The plane of sliding is observed to be the boundary between the bedrock and the highly weathered disintegrated dolomitic soil. A model to predict the progressive failure mechanism of the western flank of the landslide has also been attempted. After sliding of the material from the toe portion, the result of the FE analysis showed the probable location of $2^{\text {nd }}$ phase of detachment and with further sliding the final phase of detachment was obtained. The FE analysis results have also been validated with the field signatures.
\end{abstract}

Keywords: debris slide, finite element modelling, strength reduction factor, shear strength reduction analysis, progressive failure mechanism. 


\section{Introduction}

Slope failures have caused untold numbers of casualties and huge economic losses in India. Landslide occurrences and their consequences in the form of loss of life and property are quite significant in the state of Uttarakhand in the North Western Himalaya due to the complex geology and tectonic set up supplemented by heavy rainfall. Hence, there is a need to study the failure mechanism of potential unstable slopes to design a scheme of instrumentation for their movement monitoring and also to plan for suitable control measures.

Over the decades majority of the slope stability analysis was addressed using the limit equilibrium approaches, which is simple and widely accepted. But these techniques have limitations in handling material variation, varying geometry etc. There are also some assumptions for these techniques, for example, the side forces and their directions are assumed in order to build the equations of equilibrium. Numerical techniques are the best alternative to simulate the field situation. The finite element method represents one of the powerful alternative approaches for slope stability analysis which is accurate, versatile and requires fewer a priori assumptions. In order to find out the factor of safety (FOS) that is in accordance with the conventional limit equilibrium methods in conception, Griffiths and Lane [1] combined the finite element method (FEM) with the strength reduction technique [2] to determine the FOS. Hammah et al. [3] examined the difficulties of straight forward application of Generalized HoekBrown (GHB) criterion as a material model in Shear Strength Reduction (SSR) analysis using FEM and also suggested a solution approach that uses equivalent Mohr-Coulomb envelope in place of the Hoek-Brown failure criterion. Hammah et al. [4] proposed a method that allows direct use of the GHB criterion in finite element SSR analysis of rock slopes.

In the present research work, 2D finite element modelling of a progressive debris slide along a highly vulnerable road stretch along Chamoli-Badrinath highway (NH-58) in Garhwal Himalayas, India has been carried out. The different material properties of the debris slide as obtained from field and laboratory investigation along with some material properties as assumed from published literatures are used for finite element analysis. The 2D finite element analysis has been carried out using $\mathrm{PHASE}^{2}$ software [5]. The results obtained for this case study are presented in this paper.

\section{Landslide descriptions}

This is a debris slide of progressive nature which is encompassed by two natural streams joining the Alaknanda River at the downhill side below road level, fig. 1. The landslide is spread over a length of $112 \mathrm{~m}$ in total at the road level with two active stretches on left and right flanks having spread lengths of about $57 \mathrm{~m}$ and $15 \mathrm{~m}$ respectively. Initially, the debris slide along a narrow channel on the left flank and at the excavated height at road level was initiated, may be due to the road widening process. Due to heavy precipitation during the monsoon season 


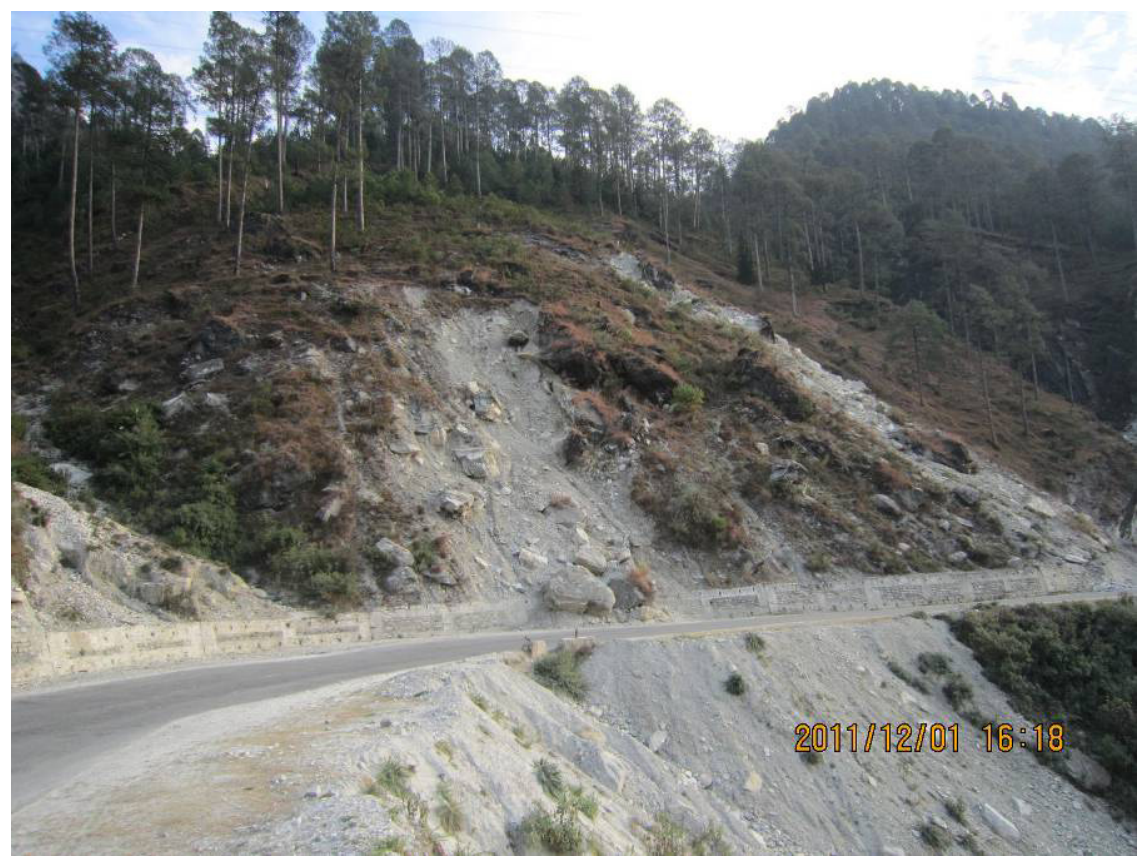

Figure 1: $\quad$ A panoramic view of the landslide.

(specifically August-September) of 2010, this slide got extended towards its right side and is also progressing towards uphill slope.

At present, the slide has the main scar on the uphill slope and a number of minor (secondary) scars developed along the radial transverse tension cracks all over the landslide body. There is a clear indication of detachment and displacement of the order of $0.5 \mathrm{~m}$ to $1.0 \mathrm{~m}$ along all these tension cracks which indicates the progressive nature of sliding activity. Only one longitudinal tension crack is observed just right side to the narrow channel of debris slide on the left flank with a visible depth of $0.3 \mathrm{~m}$ and $0.3 \mathrm{~m}$ to $0.4 \mathrm{~m}$ wide. The different features of the landslide as observed in the field are demarcated on a 1:1000 scale contour map with $2 \mathrm{~m}$ contour interval using Geographic Information System (GIS) platform, fig. 2 .

The general slope of this landslide area is $56^{\circ}$ along a direction of $\mathrm{N} 320^{\circ}$. The base rock is dolostone (dolomitic limestone). The unfavourable discontinuity has a dip of about $45^{\circ}-55^{\circ}$ with a dip direction of $\mathrm{N} 330^{\circ}$. It has a dip-slope relationship with respect to the slope direction which makes this discontinuity plane favourable for sliding along this plane. The soil overburden is about $3.6 \mathrm{~m}$ thick with two distinct layers. 


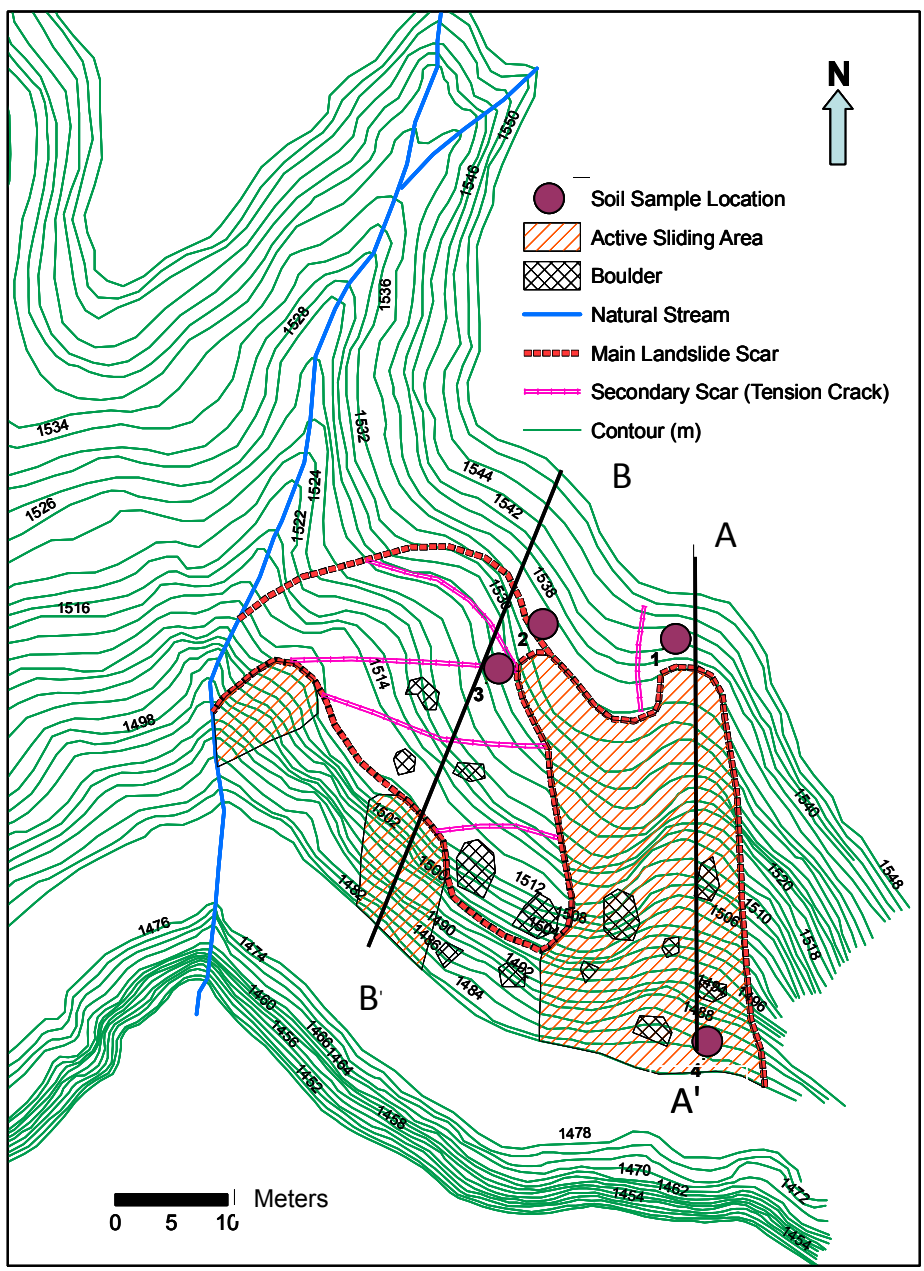

Figure 2: Field information based Landslide Map in GIS on 1:1000 scale contour map with $2 \mathrm{~m}$ contour interval.

\section{Soil sample collection and laboratory investigation}

The top soil layer appears to be fine grained and brown in colour with about $0.9 \mathrm{~m}$ thick. The second soil layer appears to be formed as a result of weathering of in-situ dolomitic parent rock, grey in colour with about $2.7 \mathrm{~m}$ thick. Below this soil layer, the in-situ rocks are present as observed in the field. The pictorial representation of these material layers along with the field photographs are given in fig. 3. 


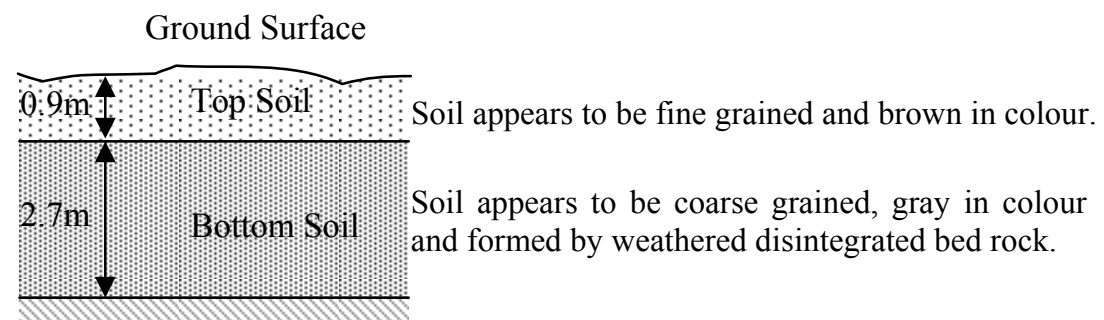

Bed Rock Dolostone. The bedding plane is acting as the surface of sliding of overlying debris/soil overburden.
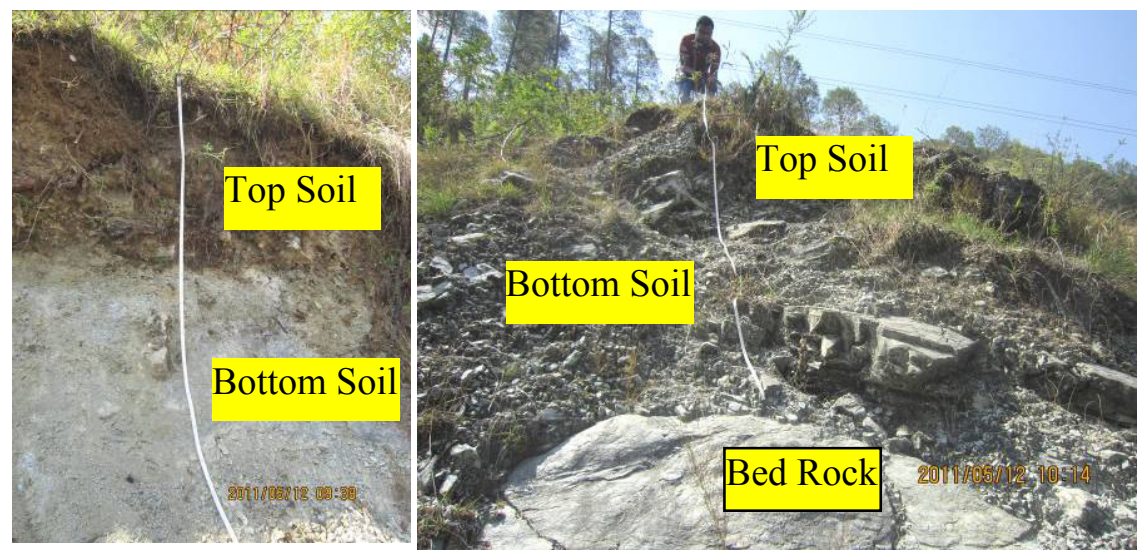

Figure 3: $\quad$ Sketch and field photographs showing different soil layers.

Four soil samples were collected from different locations at different levels of the landslide body and were tested in the laboratory to determine different material characteristics and geotechnical properties for their use in FE modelling. The characteristics of different soil samples such as grain size distribution, optimum moisture content (OMC), maximum dry density (MDD), specific gravity and permeability are given in table 1 . The cohesion and friction angle of these soils under unsaturated and saturated conditions are given in table 2 . It is observed from these data that the top soil (sample 1 and 2) contains about 62$65 \%$ of gravel and sand and $35-38 \%$ of silt and clay content with a specific gravity of 2.67. Further the cohesion under unsaturated condition for the top soil is of the order of $0.2 \mathrm{~kg} / \mathrm{cm}^{2}$ with friction angle of about $36^{\circ}-42^{\circ}$. Under saturated condition the top soil is almost cohesionless and the friction angle varies in the range of $34^{\circ}-40^{\circ}$. The bottom soil contains $70 \%$ of gravel and sand particles and $30 \%$ of silt and clay content with a specific gravity of 2.82 . The cohesion under unsaturated condition for the bottom soil is $0.07 \mathrm{~kg} / \mathrm{cm}^{2}$ with friction angle of $43^{\circ}$ and under saturated condition the bottom soil is also cohesionless with the friction angle of $38^{\circ}$. These soil properties are used for finite element modelling of the landslide. 
Table 1: $\quad$ Soil properties of different soils from the landslide body.

\begin{tabular}{|c|c|c|c|c|c|c|c|c|}
\hline \multirow[b]{2}{*}{$\begin{array}{c}\text { Soil Sample } \\
\text { Location }\end{array}$} & \multicolumn{4}{|c|}{$\begin{array}{l}\text { Grain size analysis } \\
\end{array}$} & \multicolumn{2}{|c|}{ Proctor Analysis } & \multirow{2}{*}{$\begin{array}{l}\text { Specific } \\
\text { Gravity }\end{array}$} & \multirow{2}{*}{$\begin{array}{l}\text { Permeability } \\
\text { (cm/sec) }\end{array}$} \\
\hline & $\begin{array}{c}\text { Gravel } \\
(\%)\end{array}$ & $\begin{array}{c}\text { Sand } \\
(\%)\end{array}$ & $\begin{array}{l}\text { Silt } \\
(\%)\end{array}$ & $\begin{array}{l}\text { Clay } \\
(\%)\end{array}$ & $\begin{array}{c}\text { OMC } \\
(\%)\end{array}$ & $\begin{array}{c}\text { MDD } \\
\text { (gm/cc) }\end{array}$ & & \\
\hline $\begin{array}{c}\text { Sample 1 } \\
\text { (Top Soil, } \\
\text { left flank } \\
\text { AA') }\end{array}$ & 27 & 35 & 34 & 4 & 13 & 1.97 & 2.67 & $1.08 \times 10-5$ \\
\hline $\begin{array}{c}\text { Sample 2 } \\
\text { (Top Soil, } \\
\text { left flank } \\
\text { AA') }^{\prime}\end{array}$ & 23 & 42 & 27 & 8 & 11 & 1.95 & 2.67 & \\
\hline $\begin{array}{c}\text { Sample 3 } \\
\text { (Bottom Soil, } \\
\text { right flank } \\
\text { BB') } \\
\end{array}$ & 19 & 51 & 23 & 7 & 6 & 2.22 & 2.82 & $\begin{array}{c}3.488 \times 10- \\
4\end{array}$ \\
\hline $\begin{array}{c}\text { Sample 4 } \\
\text { (Road Level, } \\
\text { left flank } \\
\text { AA') }\end{array}$ & 25 & 27 & 38 & 10 & 10 & 1.96 & 2.73 & $\begin{array}{c}1.622 \times 10- \\
5\end{array}$ \\
\hline
\end{tabular}

Table 2: $\quad$ Shear parameters of different soils from the landslide body.

\begin{tabular}{|c|c|c|c|c|}
\hline \multirow{2}{*}{ Soil Sample Location } & \multicolumn{4}{|c|}{ Direct Shear } \\
\cline { 2 - 5 } & \multicolumn{2}{|c|}{ Unsaturated } & \multicolumn{2}{c|}{ Saturated } \\
\cline { 2 - 5 } & $\begin{array}{c}\text { Cohesion } \\
\left(\mathrm{kg} / \mathrm{cm}^{2}\right)\end{array}$ & $\begin{array}{c}\text { Angle of Friction } \\
(\mathrm{deg})\end{array}$ & $\begin{array}{c}\text { Cohesion } \\
\left(\mathrm{kg} / \mathrm{cm}^{2}\right)\end{array}$ & $\begin{array}{c}\text { Angle of Friction } \\
(\mathrm{deg})\end{array}$ \\
\hline $\begin{array}{c}\text { Sample 1 } \\
(\text { Top Soil, left flank } \\
\text { AA') }\end{array}$ & 0.20 & 42 & 0.04 & 40 \\
\hline $\begin{array}{c}\text { Sample 2 } \\
\left(\begin{array}{c}\text { (To Soil, left flank } \\
\text { AA') }\end{array}\right.\end{array}$ & 0.20 & 36 & 0 & 34 \\
\hline $\begin{array}{c}\text { Sample 3 } \\
(\text { Bottom Soil, right } \\
\text { flank BB') }\end{array}$ & 0.07 & 43 & 0 & 38 \\
\hline $\begin{array}{c}\text { Sample 4 } \\
(\text { Road Level, left flank } \\
\text { AA') }\end{array}$ & 0.20 & 38 & 0 & 33 \\
\hline
\end{tabular}

\section{Finite element approach}

The finite element (FE) method represents a powerful alternative approach for slope stability analysis which is accurate, versatile and requires fewer a priori assumptions, especially regarding the failure mechanism. The finite element approach may be valuable if awkward geometries or material variation are encountered which are difficult to solve using traditional methods. Several commercial FE packages are available which handles the complexity of the calculation. The graphical capabilities of FE programs also allow better understanding of the mechanisms of failure. Researchers $[1,6,7]$ applied FE for slope stability analysis and obtained good agreement with slip circle solutions. The advantages of a finite element approach for slope stability analysis over 
traditional limit equilibrium method can be summarized as follows: (1) no assumption needs to be made in advance about the shape or location of the failure surface. Failure occurs "naturally" through the zone within the soil mass in which the soil shear strength is unable to resist the applied shear stresses, (2) since there is no concept of slice in the FE approach there is no need for assumptions about slice forces. The FE method preserves global equilibrium until "failure" is reached and (3) the FE method is able to monitor progressive failure up to and including global failure.

Factor of safety of a slope is defined as the factor by which the original shear strength parameter is divided in order to bring the slope to the point of failure. If the material model is Mohr-coulomb model then the factored shear strength parameters $c_{f}$ and $\varphi_{f}$, are therefore given by:

$$
\begin{gathered}
c_{f}=\frac{c}{S R F} \\
\varphi_{f}=\tan ^{-1}\left(\frac{\tan \varphi}{S R F}\right)
\end{gathered}
$$

where, SRF is a "Strength Reduction Factor". This method is referred to as the "shear strength reduction technique" [2].

\section{Results and discussions}

Slope profiles along two different critical sections (fig. 4) of the slope (AA' and $\mathrm{BB}^{\prime}$ as shown in fig. 2) are drawn to perform finite element modelling of the debris slide along these real geometry sections. Two dimensional (2D) plain strain FE modelling is carried out on these profiles. Shear Strength Reduction (SSR) analysis is performed with $\mathrm{PHASE}^{2}$, a 2-dimensional elasto-plastic FE program. PHASE ${ }^{2}$ performs a systematic search for the critical SRF that will just cause the slope to fail.

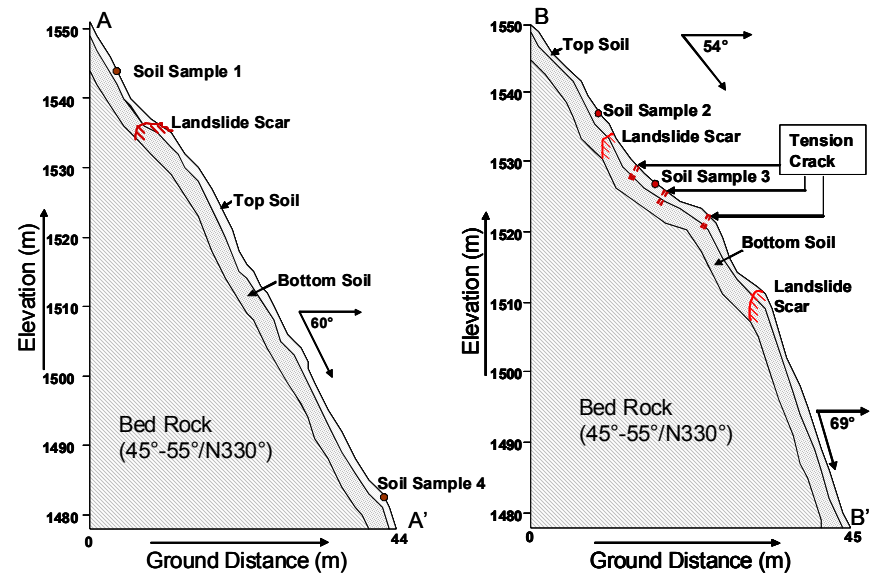

Figure 4: $\quad$ Slope profiles along (a) AA' section and (b) BB' section. 
According to Griffiths and Lane [1], in the absence of value of Elastic modulus (E) and Poisson's ratio (v), E $=10^{5} \mathrm{kN} / \mathrm{m}^{2}$ and $v=0.3$ for the top soil layer have been assumed. The top soil material was modelled according to Mohr-Coulomb model. Generalized Hoek-Brown criterion was used as material model for bedrock as well as weathered disintegrated dolomitic soil layer (i.e., bottom soil). The reason for using Generalized Hoek-Brown criterion for the bottom soil is that the bottom soil condition is treated as highly weathered and disintegrated dolomitic rock. Geological Strength Index (GSI), uniaxial compressive strength $\left(\sigma_{\mathrm{ci}}\right)$ and material constant $\left(m_{i}\right)$ were assumed from the chart provided by Marinos and Hoek [8]. Roclab 1.0 software [9] was used to calculate the constants required for the criterion. On the basis of GSI and $\sigma_{\mathrm{ci}}$, elastic modulus (E) was determined from the chart [10]. These material models and material properties are listed in table 3.

Table 3: $\quad$ Material model and properties used for FE modelling of the slope.

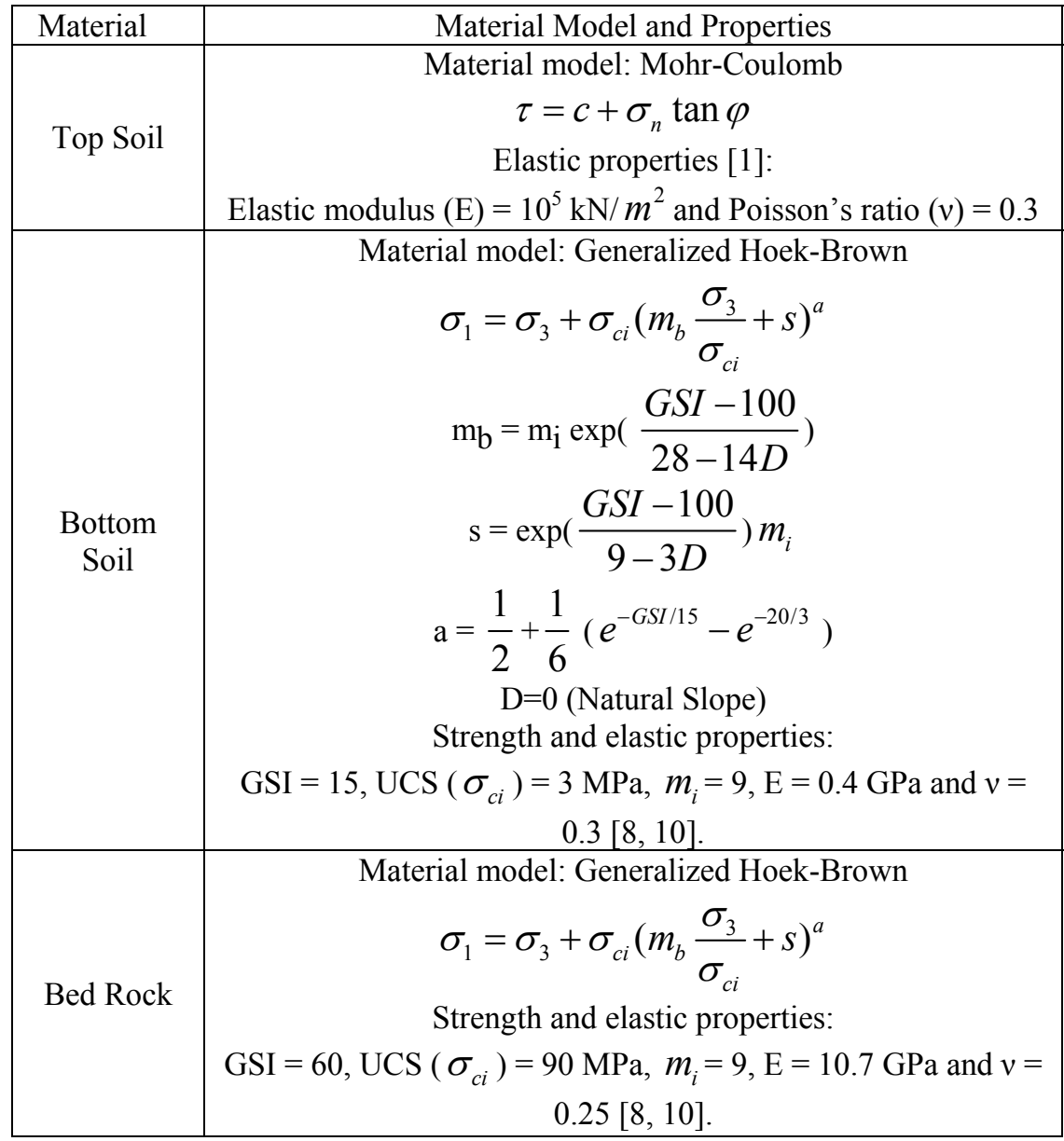


As far as the boundary conditions are concerned, the slope face was kept free and other continuous boundaries were restrained against any movement in the $\mathrm{x}$ and y direction. A minimum of 10000 finite elements are used to discretize the model. In the loading step each finite element is given both an initial stress and a body force (self weight). The initial vertical stress is estimated from the weight of the material above the element. $\mathrm{PHASE}^{2}$ automatically determines the ground surface above the element and the stress due to the material above the element. In the absence of actual horizontal to vertical stress ratio, the horizontal stress is assumed to be equal to the vertical stress (hydrostatic stress condition). This assumption is not unreasonable. This is the assumption made in the slope stability verification examples [4]. The body force is calculated using the unit weight defined for the material in the material properties. Shear Strength Reduction analysis (dry analysis) was performed using $\mathrm{PHASE}^{2}$ to determine the critical SRF.

After the SSR analysis we could observe that the critical SRF is 0.54 for the AA' profile section on the left flank of the debris slide, fig. 5. As per the analysis result, the displacement in case of AA' profile are of the order of $13.2 \mathrm{~mm}$. Similarly, the critical SRF is 0.53 for the BB' profile section on the right flank of the debris slide, fig. 6. As per the analysis result, the displacement in case of BB' profile are of the order of $4.8 \mathrm{~mm}$. This indicates that the slope is highly unstable on both left (eastern) and right (western) flanks. The results show very good correlation with the real field situation. As we could observe from both the profiles of the landslide flanks, the locations of the landslide scars, from where the sliding processes have already been initiated, match exactly with the FE analysis result. According to the analysis result, the plane of slide is observed to be the boundary between the bedrock and the highly weathered disintegrated dolomitic soil. This interpretation has also been confirmed in the field scenario.
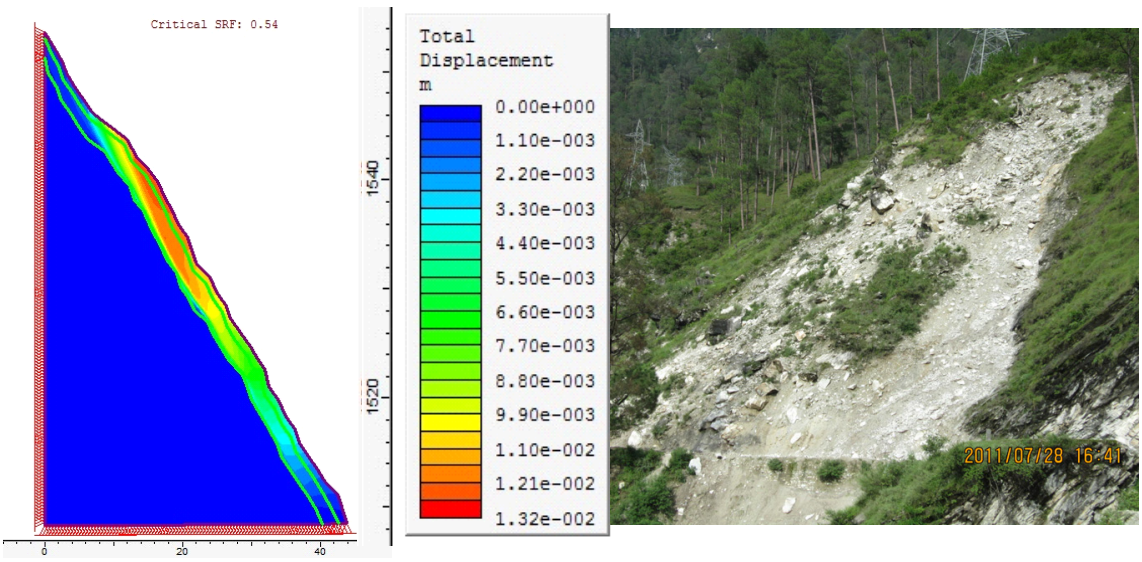

Figure 5: SSR analysis results along with field photograph for AA' profile along the eastern flank of the debris slide. 

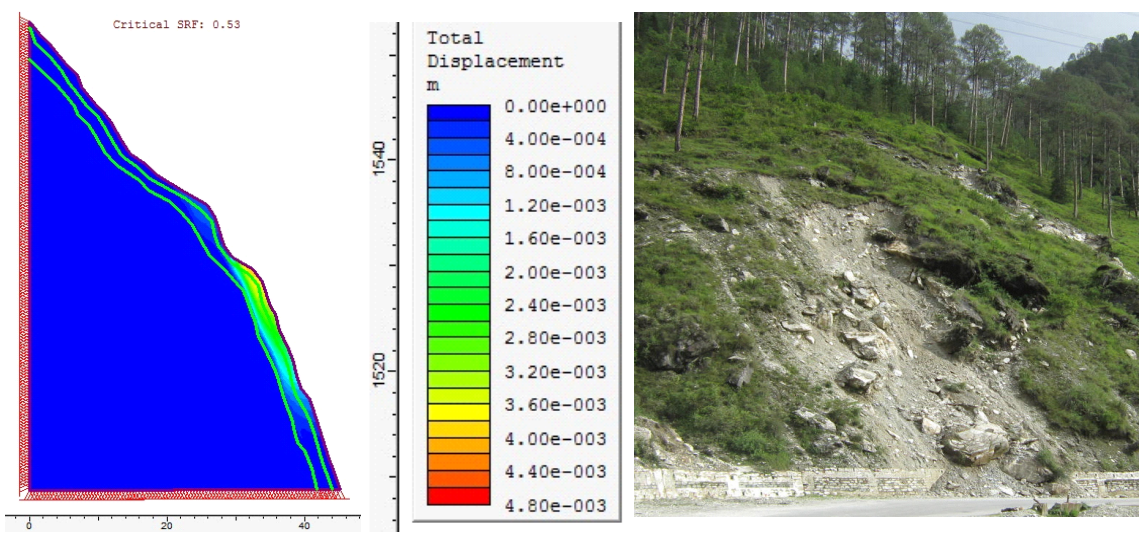

Figure 6: SSR analysis results along with field photograph for BB' profile along the western flank of the debris slide.

A model to predict the progressive failure scenario of the western flank of the landslide (along BB' profile) has also been attempted. After removal of the unstable material from the toe portion, the result of the FE analysis showed the probable location of $2^{\text {nd }}$ phase of detachment. Further, after removal of unstable material observed in the $2^{\text {nd }}$ phase the final phase of detachment was obtained. These analysis results are given in fig. 7. The critical SRF obtained are 0.53 and 0.9 for both the phases of failure with the displacements of the order of $0.72 \mathrm{~mm}$ and $14.4 \mathrm{~mm}$ respectively. These results have also been validated with the field signatures and it was observed that the progressive detachment zones as obtained through FE analysis matched with the tension cracks developed on the uphill slope of the landslide (fig. 4b).
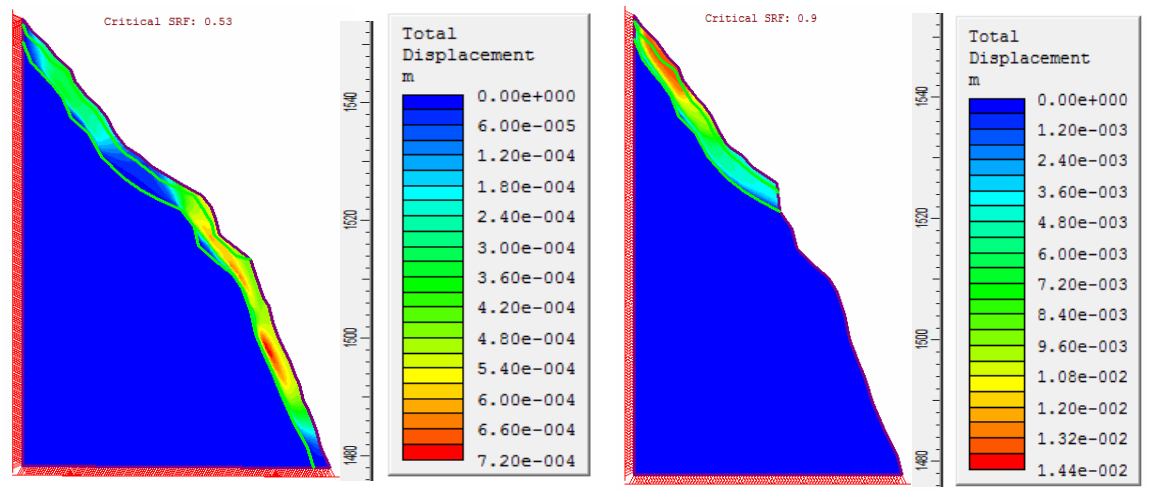

Figure 7: $\quad$ SSR analysis of BB' profile for progressive failure after removal of the unstable portion of the material in two phases. 


\section{Conclusions}

Landslide modelling using finite element analysis considering the real geometry and material properties of the slope is still in its exploratory stage in Indian context. In the present research, the results of $2 \mathrm{D}$ finite element modelling of a progressive debris slide are presented. The analysis results validate and confirm the already initiated failure zones and expected progressive failure zones as also observed in the field. It may be inferred that the geometry of the slope, material profile and characteristics along the slope are the most crucial data for accurate modelling of a potential landslide. Also, it is observed that finite element based modelling is a quite powerful tool to simulate the near-real model of a landslide, if the modelling parameters are actual based on the field and laboratory investigations.

Modelling has manifold utility for landslide disaster mitigation in terms of identifying stress accumulation zones and also the extent of displacement expected to occur for locating and planning strengthening measures at such zones within a specific landslide. It also can help in accurately locating the sites for placement of sensors for instrumentation and monitoring of actual ground movements in a landslide.

\section{Acknowledgement}

The authors are grateful to the Director, CSIR-CBRI for his kind permission to publish the work.

\section{References}

[1] Griffiths, D.V and Lane, P.A., Slope stability analysis by finite element. Geotechnique, 49(3), pp. 387-403, 1999.

[2] Matsui, T. and Sam, K.C., Finite element slope stability analysis by shear strength reduction technique. Soils Found., 32(1), pp. 59-70, 1992.

[3] Hammah, R.E., Curran, J.H., Yacoub, T.E. and Corkum, B.C., Stability analysis of rock slope using the finite element method. Proc. of the ISRM Regional Symp. EUROCK 2004 and 53rd Geomechanics Colloquium. Salzburg, Austria, 2004.

[4] Hammah, R.E., Yacoub, T.E., Corkum, B.C. and Curran, J.H., The shear strength reduction method for the Generalized Hoek-Brown criterion. Proc. $40^{\text {th }}$ U.S. Symp. on Rock Mechanics (USRMS): Rock mechanics for Energy, Minerals and infrastructure development in the northern regions, Anchorage, Alaska, ARMA/USRMS 05-810, 2005.

[5] Rocscience, A 2D finite element program for calculating stresses and estimating support around the underground excavations. Geomechanics software and Research, Rocscience INC, Toronto, Canada, 2006.

[6] Smith, I.M. and Hobbs, R., Finite element analysis of centrifuged and builtup slopes. Geotechnique, 24(4), pp. 531-559, 1974. 
[7] Zienkiewicz, O.C. and Taylor, R.L., The finite element method, Volume 1, $4^{\text {th }}$ edition. McGraw Hill: London and New York, 1989.

[8] Marinos, P. and Hoek, E., GSI: A geologically friendly tool for rock mass strength estimation. Proc. of the GeoEng2000 at the Int. conf. on Geotechnical and Geological Engineering, Melbourne. Technomic publishers: Lancaster, pp. 1422-1446, 2000.

[9] Roclab, 2007. Rocscience Geomechanics software and research, Toronto, Canada Online http://download.rocscience.com/ordering/Free DownloadsForm.asp

[10] Cai, M., Kaiser, P.K., Uno, H., Tasaka, Y. and Minami, M., Estimation of rock mass deformation modulus and strength of jointed hard rock masses using the GSI system. Int. J. Rock Mech. Min. Sci., 41, pp. 3-19, 2004. 